\title{
Surface modification of W9Cr4V2Mo high-temperature bearing steel by rare earth ion implantation
}

\author{
Fanya Jin ${ }^{\mathrm{a}, \mathrm{b}}$, Paul K. Chu ${ }^{\mathrm{b}, *}$, Zejin $\mathrm{Xu}{ }^{\mathrm{a}}$, Jiaxue Zhao ${ }^{\mathrm{a}}$, Ming Zhu ${ }^{\mathrm{a}}$, \\ Ricky K.Y. Fu ${ }^{\text {b }}$, Honghui Tong ${ }^{\text {a }}$ \\ ${ }^{a}$ Southwestern Institute of Physics, Chengdu, 610041, Sichuan, China \\ ${ }^{\mathrm{b}}$ Department of Physics and Materials Science, City University of Hong Kong, Tat Chee Avenue, Kooloon, Hong Kong, China
}

Available online 27 September 2006

\begin{abstract}
Wear and corrosion are the main failure mechanisms of bearings and it is important to prolong their working lifetimes by improving the bearing surface properties. Incorporation of rare-earth elements is one of the viable means in many technologies such as plating, chemical heat treatment, and thermal spraying. In this work, various kinds of rare earth ions including praseodymium, lanthanum and neodymium were implanted into W9Cr4V2Mo high-temperature bearing steel specimens using a metal vapor vacuum arc source. Pin-on-disk wear tests and microhardness and potentiodynamic polarization measurements were employed to evaluate the mechanical properties and chemical stability of the treated specimens. The chemical composition and surface morphology of the implanted layers were characterized by X-ray photoelectron spectroscopy (XPS) and scanning electron microscopy (SEM). Our results indicate that the tribological characteristics of the treated samples are affected significantly due to the smoother and harder surface, while the enhancement of the corrosion resistance in the $3.5 \mathrm{wt} \% \mathrm{NaCl}$ aqueous solution after ion implantation is not appreciable. The modified surface yields better wear resistance.
\end{abstract}

(C) 2006 Elsevier B.V. All rights reserved.

Keywords: Bearing steel; Rare earth ion implantation; Surface modification

\section{Introduction}

Wear and corrosion are the main failure mechanisms of bearings and some measures have been proposed to prolong the working lifetime. Possible approaches include the use of more expensive materials, ion implantation, surface finish enhancement, and ion beam assisted deposition [1-5]. Among them, ion implantation is used extensively for the modification of surface and properties of materials and many studies have shown that the bearing steel surface can be strengthened by ion implantation of different elements such as $\mathrm{N}, \mathrm{Mo}, \mathrm{N}$ and Mo, and so on [6,7]. Recently, rare earths have attracted attention as reinforcing elements in applications such as plating, chemical heat treatment and thermal spraying. For instance, rare earth ion implantation has been utilized to enhance the high temperature oxidation behavior of metals and improve the aqueous corrosion resistance [8-12]. However, to our knowledge, a systematic investigation of rare earth ion implantation on the mechanical properties and chemical

\footnotetext{
* Corresponding author. Tel.: +852 27887724; fax: +852 27889549.

E-mail address: paul.chu@cityu.edu.hk (P.K. Chu).
}

stability of bearing steels has not been conducted. In this work, the effects of ion implantation of rare-earth elements, $\mathrm{Pr}$, La and Nd, on the surface hardness, tribological behavior, corrosion resistance, and wear resistance of W9Cr4V2Mo bearing steels were examined.

\section{Experimental details}

Round W9Cr4V2Mo bearing steel disks (20 $\mathrm{mm}$ in diameter and $5 \mathrm{~mm}$ thick) composed of approximately 9-10 wt.\% W, 4-5 wt.\% Cr, 1-2 wt.\% V, 1-1.5 wt.\% Mo, and the balance Fe were used as the substrates. The samples were mechanically ground with waterproof abrasive paper up to 2000 grit size and ultrasonically cleaned in acetone before ion implantation. Ion implantation was carried out by means of a metal vapor vacuum arc source at a base pressure of $<8 \times 10^{-4} \mathrm{~Pa}$. The detailed implantation parameters are listed in Table 1.

The surface characteristics of the untreated and ion implanted specimens were evaluated by scanning electron microscopy (SEM, JEOL JSM-820). X-ray photoelectron spectroscopy (XPS) was conducted to analyze the chemical structure of the modified surface and the sputtering rate was about $4.74 \mathrm{~nm} / \mathrm{min}$. Surface 
Table 1

Rare earth ion implantation instrumental parameters

\begin{tabular}{llll}
\hline Materials & W9Cr4V2Mo & W9Cr4V2Mo & W9Cr4V2Mo \\
\hline Implanted element & $\mathrm{Pr}$ & $\mathrm{La}$ & $\mathrm{Nd}$ \\
Extraction voltage & $40 \mathrm{kV}$ & $40 \mathrm{kV}$ & $40 \mathrm{kV}$ \\
Bulk temperature & $<150{ }^{\circ} \mathrm{C}$ & $<150{ }^{\circ} \mathrm{C}$ & $<150{ }^{\circ} \mathrm{C}$ \\
Ion beam current & $4 \mathrm{~mA}$ & $4 \mathrm{~mA}$ & $4 \mathrm{~mA}$ \\
Dose & $1 \times 10^{17}$ ions cm $^{-2}$ & $1 \times 10^{17}$ ions cm $^{-2}$ & $1 \times 10^{17}$ ions cm $^{-2}$ \\
\hline
\end{tabular}

hardness was evaluated by means of Vickers indentation under a load of 10 and $100 \mathrm{~g}$ with $10 \mathrm{~s}$ dwell time. The friction coefficients were measured using a computer-controlled oscillating ball-ondisk scratch tester equipped with a $5 \mathrm{~mm} \mathrm{WC}$ ball. The wear tests were conducted in air under a load of $0.4 \mathrm{~N}$ with a rotation diameter of $5 \mathrm{~mm}$ and sliding speed of $200 \mathrm{rpm}$. The width and depth of the wear tracks were determined using a Taylor-Hobson/ Form Talysurf PGI surface texture tester. Potentiodynamic tests were performed in a $3.5 \mathrm{wt} . \% \mathrm{NaCl}$ solution at room temperature and all the electrochemical potential measurements were taken with a saturated calomel electrode (SCE).

\section{Results and discussion}

After praseodymium, lanthanum and neodymium ion implantation, the surface roughness of the substrates appears
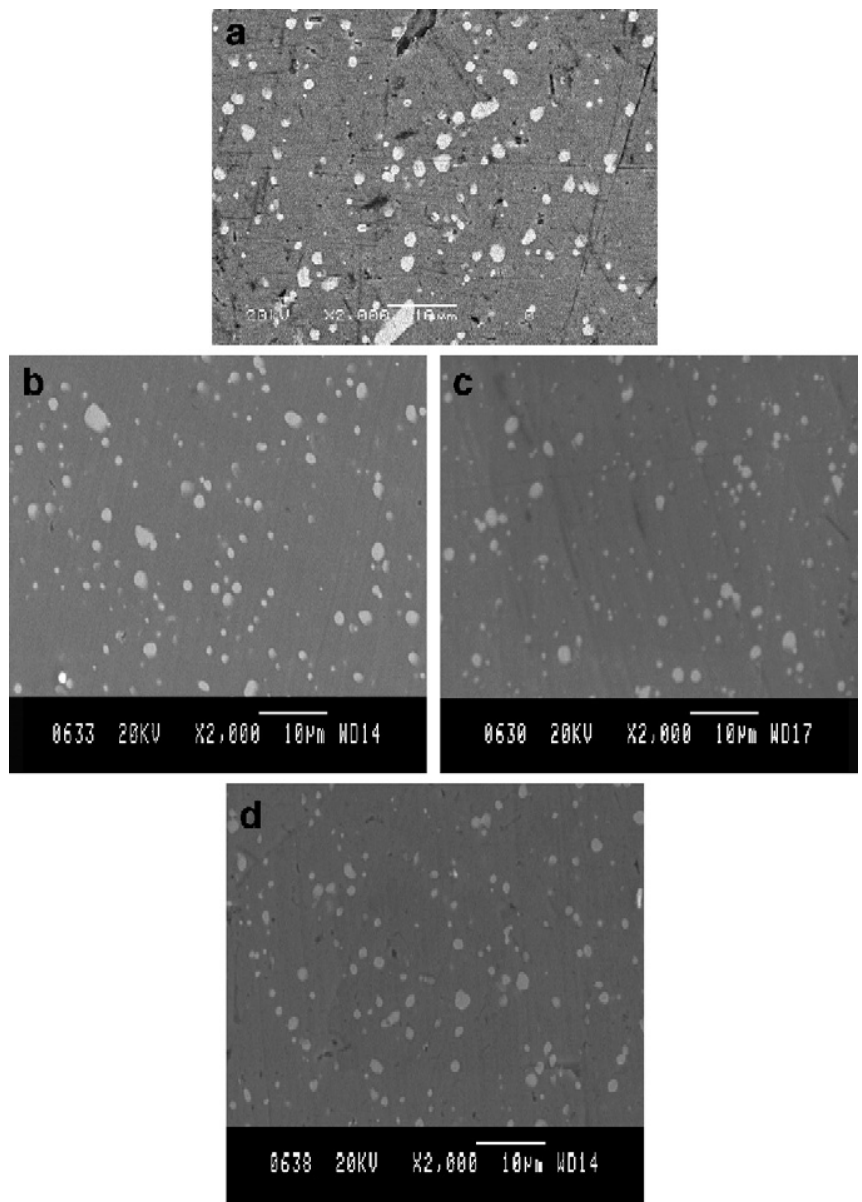

Fig. 1. SEM images showing the surface morphology of the samples: (a) untreated, (b) Pr implanted, (c) La implanted, and (d) Nd implanted. to have been somewhat reduced compared to the untreated substrate (see Fig. 1). This smoothening effect may have been due to the ion beam sputtering during ion implantation. From the XPS results in Fig. 2, surface oxide layers in the form of $\mathrm{Pr}_{2} \mathrm{O}_{3}, \mathrm{La}_{2} \mathrm{O}_{3}$, or $\mathrm{Nd}_{2} \mathrm{O}_{3}$ are formed and the thickness of all the ion implanted layers is about $40 \mathrm{~nm}$. This suggests surface oxidation during ion implantation in spite of the base pressure of $8 \times 10^{-4} \mathrm{~Pa}$ and that there is strong affinity between the rareearth elements and residual oxygen within the vacuum chamber.
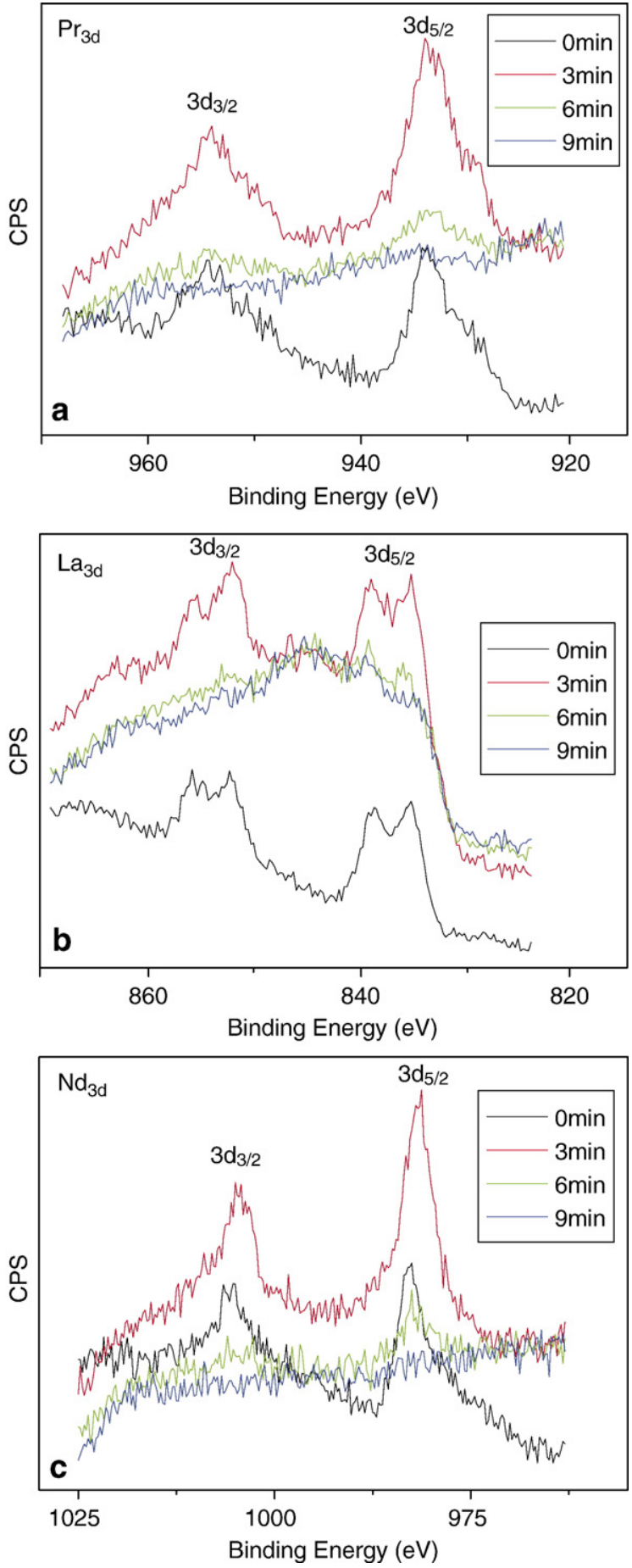

Fig. 2. XPS spectra acquired from the samples: (a) Pr implanted, (b) La implanted, and (c) Nd implanted. 


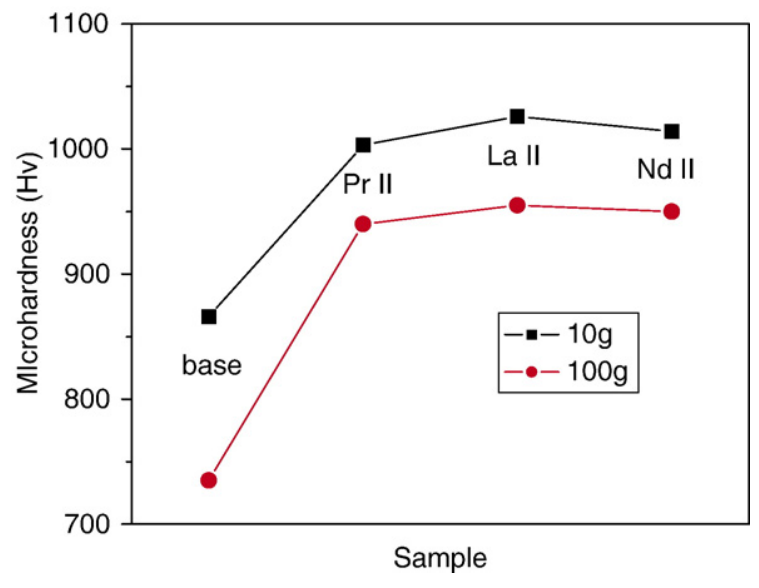

Fig. 3. Microhardness values measurements of the untreated and ion implanted substrates using $10 \mathrm{~g}$ and $100 \mathrm{~g}$ loads.

After ion implantation, all the implanted samples exhibited increased microhardness of 20 to $30 \%$ as shown in Fig. 3. The observed increase in the surface hardness is believed to be due to implantation induced defects and dislocation effects. Addition of a large number of rare-earth elements into the substrate surface has been shown to give rise to dislocation and point defects causing hardening [4].

The effects of praseodymium, lanthanum and neodymium ion implantation on the friction and wear behavior of W9Cr4V2Mo bearing steels are shown in Fig. 4. It can be seen that the untreated sample has a relatively high friction coefficient $(0.2-$ 0.55). In contrast, the friction coefficients of the implanted samples are reduced to $0.15-0.2$. The relative difference among the three elements is not appreciable. In order to better understand the wear behavior of the untreated and ion implanted samples, the wear tracks obtained using a surface texture tester are displayed in Fig. 5. The unimplanted sample shows a deep and wide wear groove, whereas the implanted samples exhibit narrow and more compact grooves, especially the La ion implanted sample. The improvement is believed to stem from the smoothing of the surface as well as surface hardening due to ion implantation.

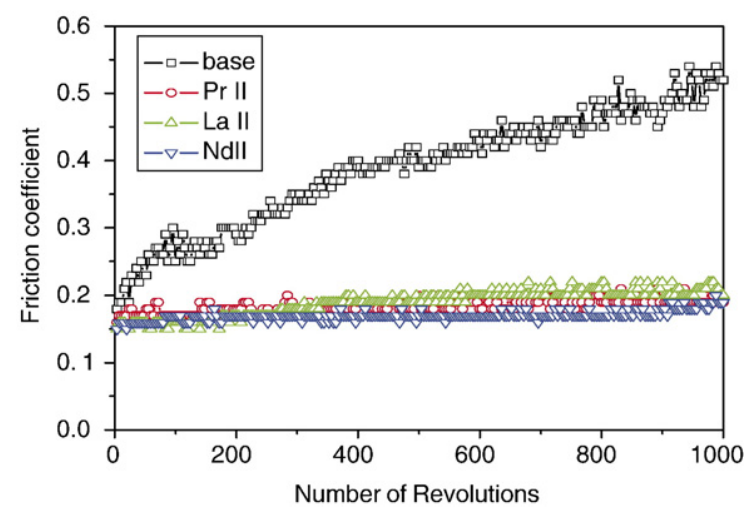

Fig. 4. Friction coefficients as a function of sliding turns measured from the untreated and ion implanted substrates.

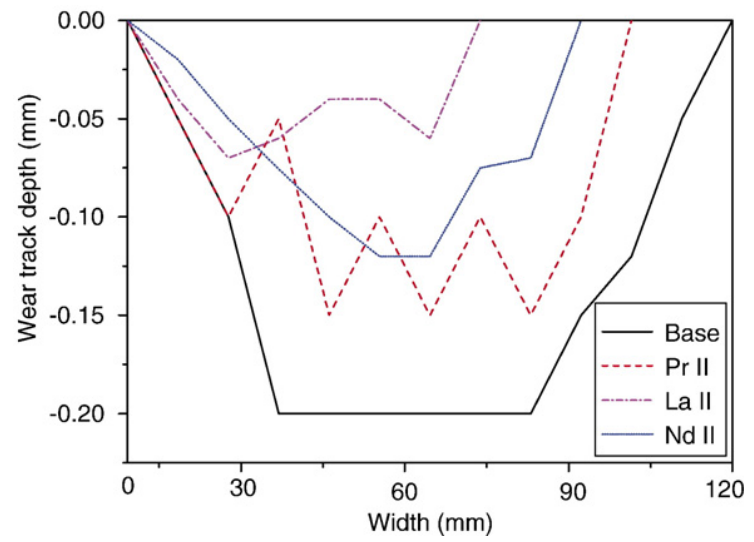

Fig. 5. Width and depth of wear tracks obtained from the untreated and ion implanted substrates.

Fig. 6 summarizes the potentiodynamic polarization curves of the samples. It can be observed that the corrosion resistance is not significantly enhanced by rare earth ion implantation based on the corrosion potential and corrosion current. In comparison, the corrosion resistance in aqueous solution has been reported to improve by adding rare-earth elements which form oxide dispersoids and oxide barriers [13]. In this work, the corrosion resistance is perhaps predominantly affected by the amount of $\mathrm{Cr}$ in the W9Cr4V2Mo bearing steels.

\section{Conclusion}

Praseodymium, lanthanum and neodymium ion implantation were performed on W9Cr4V2Mo high-temperature bearing steel substrates. Based on the XPS results, the implanted surface contains the rare earth oxides. The modified surface yields better wear resistance, possibly due to the smoother and harder surface. However, the enhancement of the corrosion resistance in $3.5 \mathrm{wt} . \% \mathrm{NaCl}$ aqueous solution after ion implantation is not appreciable possibly because the corrosion resistance of W9Cr4V2Mo bearing steel is dominated by the chromium content in the bearing steels.

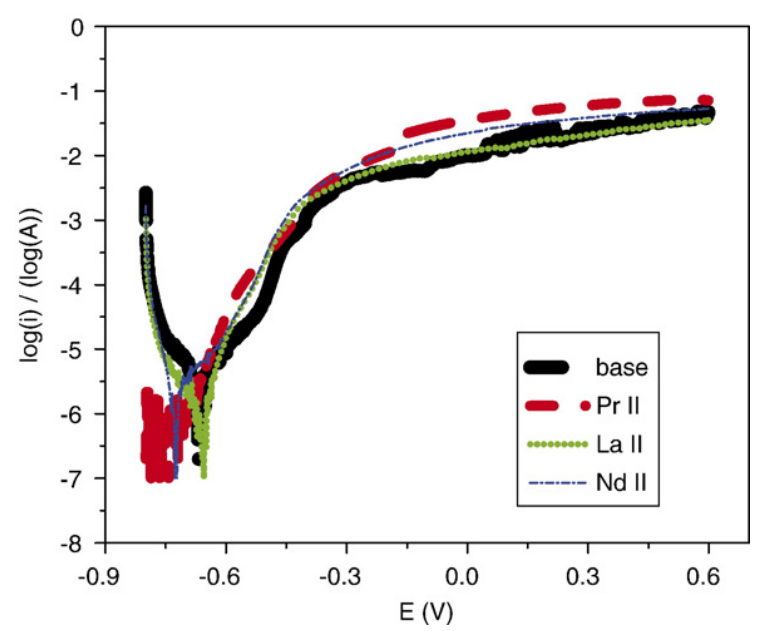

Fig. 6. Potentiodynamic polarization curves generated for the untreated and ion implanted substrates in $3.5 \% \mathrm{NaCl}$ solution. 


\section{Acknowledgement}

This work was supported by City University of Hong Kong Direct Allocation Grant \#9360110.

\section{References}

[1] F.S. Shieu, L.H. Cheng, M.H. Shiao, Thin Solid Films 311 (1997) 138.

[2] K.H. Lee, C.H. Park, Y.S. Yoon, Surf. Coat. Technol. 142-144 (2001) 971.

[3] M. Bromark, M. Larsson, P. Hedenqvist, Surf. Coat. Technol. 90 (1997) 217.

[4] R.K.Y. Fu, K.L. Fu, X.B. Tian, P.K. Chu, J. Vac. Sci. Technol., A 22 (2) (2004) 356.

[5] F.Y. Jin, H.H. Tong, L.R. Shen, Q.C. Chen, K. Wang, P.K. Chu, Plasma Sci. Technol. 7 (2005) 2959.
[6] J.C. Jin, B.L. Wang, Z.H. Zhu, H.Z. Chen, C.G. Zhao, J.S. Wu, J. Hum. Univ. 14 (4) (1984) 65.

[7] H. Dimigen, Mater. Sci. Eng. 69 (1984) 181

[8] J.C. Jin, H. Jin, M. Sakai, C.L. Wu, Wear 205 (1997) 214.

[9] Y.F. Lian, Q.J. Xue, H.Q. Wang, Surf. Coat. Technol. 73 (1995) 98.

[10] D.Q. Peng, X.D. Bai, X.W. Chen, Q.G. Zhou, Surf. Coat. Technol. 165 (2003) 268.

[11] C.M. Abreu, M.J. Critobal, X.R. Novoa, G. Pena, M.C. Perez, R.J. Rodriguez, Surf. Coat. Technol. 158-159 (2002) 582.

[12] M.A. Arenas, J.J. de Damborenea, A. Medrano, J.A. Garcia, R. Rodriguez, Surf. Coat. Technol. 158-159 (2002) 615.

[13] D.Q. Peng, X.D. Bai, X.W. Chen, Q.G. Zhou, X.Y. Liu, R.H. Yu, Vacuum 72 (2004) 313. 